\section{Managing cleft lip and palate}

\section{Editorial proves controversial}

EDITOR,-In their two year Medline search for studies on the results of cleft surgery Tony Markus and Peter Ward Booth found just one British study, and they criticise the lack of British studies. Six studies on primary and secondary surgery and outcome analysis are noteworthy, ${ }^{2-7}$ as is a book on speech. ${ }^{8}$

Citing just the Eurocleft study, which included two British centres, Markus and Ward Booth state that British results are poor. This is not true in other British studies. ${ }^{910}$ The authors neglect to mention that the two centres with the best results in the Eurocleft study used different surgical techniques (none like Markus's) and high volume operators (none of them maxillofacial surgeons). On high volume operators Markus and Ward Booth are incoherent. They move from implying that specialist high volume operators are preferable to stating that high volume operators and large, centralised units do not guarantee good results, while high volume maxillofacial surgery exists in district hospitals, which are well placed to provide a comprehensive service.

European countries, including Britain, have made advances in cleft surgery. "Continental Europe may do it better"- - or it may not. Early cleft bone grafting was once strongly advocated in Germany, but further studies in, for example, Britain and Germany led to its being abandoned." For years the technique of delayed hard palate closure of Schweckendiek in Germany was considered to be good, until it was reported to give poor results in terms of speech. ${ }^{12}$ Other studiesfor example, one in Britain - had earlier shown worse speech after delayed hard palate closure. ${ }^{1}$

Two French cleft surgeons, Malek and Delaire, are known internationally. Delaire never kept detailed records and did not publish his results. Nevertheless, Markus uses Delaire's technique and states that it "results in better function and more normal growth and development." ${ }^{\prime \prime}$ There is no evidence for this in the references given.

Markus labels his surgery functional surgery, as if functional surgery for clefts is new. This is not so. Functional surgery for clefts, based on studies of function and anatomy, has been done for decades. ${ }^{11}$

"Studies comparing this technique with those commonly used in Britain suggest that functional surgery produces consistently better results." This is not true. The reference cited ${ }^{13}$ describes a treatment regimen different from that used by

\section{Advice to author}

We prefer short letters that relate to recently published article and we are unlikely to publish letters longer than 400 words and containing over five references. Letters may be shortened. Your letters should be typed with double spacing and include a word count. All authors need to sign the letter and provide one current appointment and address. We encourage you to declare any conflict of interest. Please enclose a stamped addressed envelope if you require an acknowledgment.
Markus. The study patients were compared with historical controls, whose lip repair is not described in detail, whose palate repair is not known to be used by anyone in Britain, ${ }^{14}$ and whose surgery was performed later than is now common in Britain. ${ }^{14}$ One surgeon has also had problems, including a "major problem" with fistulas, with the Markus technique. ${ }^{15}$

Markus and Ward Booth are right to question everything. They must also be questioned. As a surgeon, I am embarrassed by their indifference to facts and clear thinking. It will be difficult to believe them in future. I am disappointed that the $B M \mathcal{F}$ published their superficial, misleading, and self promoting piece. Patients, parents, and others deserve a better discussion of the multidisciplinary issues of cleft lip and palate.

M JTIMMONS

Bradford Royal Infirmary

Consultant Bradford Royal In

1 Markus T, Ward Booth P. Managing cleft lip and palate. $B M f$ 1995;311:765-6. (23 September.)

Zhu NW, Senewiratne S, Pigott RW. Lip posture and mouth width in children with unilateral cleft lip. $\mathrm{Br} \mathcal{F}$ Plast Surg 1994;47:301-5.

3 Jiginni V, Kangesu T, Sommerlad BC. Do babies require arm splints after cleft palate repair? Br f Plast Surg 1993;46:681-5.

Sommerlad BC, Henley M, Birch M, Harland K, Moiemen N, Boorman JG. Cleft palate re-repair-a clinical and radiographic study of 32 consecutive cases. Br f Plast Surg 1994;47:406-10.

5 Mackay F, Bottomley J, Semb G, Roberts C. Dentofacial form in the five-year-old child with unilateral cleft lip and palate. Cleft Palate Craniofac 7 1994:31:372-5.

6 Sell D, Harding A, Grunwell P. A screening assessment of cleft palate speech (Great Ormond Street speech assessment). Eur 7 Discord Commun 1994;29:1-15.

7 Peat BG, Albery EH, Jones K, Pigott RW. Tailoring velopharyngeal surgery: the influence of etiology and type of operation. Plast Reconser Surg 1994:93:948-53.

8 Grunwell P, ed. Analysing cleft palate speech. London: Whurr, 1993.

9 Christie FB, Stirrups DR, Mackenzie JS, Lawrence GM. An orthodontic evaluation of 16-year-old males with an original complete unilateral cleft lip and palate problem repaired during the neonatal period. Br f Plast Surg 1991;44:557-61.

10 Cussons PD, Murison MSC, Fernandez AEL, Pigott RW. A panel based assessment of early versus no nasal correction of the cleft lip nose. Br f Plast Surg 1993;46:7-12.

11 Millard DR Jr. Cleft craft. Vols 1, 2, 3. Boston: Little Brown, 1976-80.

12 Rohrich RJ, Byrd HS. Optimal timing of cleft palate closure: speech, facial growth and hearing considerations. Clin Plast Surg 1990;17:27-36.

13 Joos U. Skeletal growth after muscular reconstruction for cleft lip. Alveolus, and palate. Br $f$ Oral Maxillofac Surg 1995;33: 139-44.

14 Asher-McDade C, Shaw WC. Current cleft lip and palate management in the United Kingdom. Br $\mathcal{f}$ Plast Surg 1990;43:318-21.

15 Pospisil OA. Personal experience with primary functional dual repair of cleft lip and palate [abstract]. $\mathrm{Br} \mathcal{F}$ Oral Maxillofac Surg 1995;33:122.

\section{Trials of management are inevitably long}

EDrToR,-In their editorial Tony Markus and Peter Ward Booth ${ }^{1}$ seek to discredit the work of most British surgeons working in cleft lip and palate on the basis of results in patients treated in the 1970 s published by Shaw et al. ${ }^{2}$ They imply that no lessons have been learnt and state that the "functional repair" of Delaire produces vastly superior results. However, Delaire failed to publish his results, and Markus and Ward Booth merely reiterate his hypothesis. The almost identical technique of Malek produced as good but not better results than those achieved in Toronto by the Langenbeck technique when assessed by an independent authority. ${ }^{3}$
But let us suppose Delaire is right. It will be appreciated that one cannot take up every good idea that comes along when one is in the middle of a trial. In a career that started in 1969, with a caseload equivalent to that of Markus, it has taken me nearly 25 years to get articles published on a sufficient number of cases treated 10 years ago by the Veau technique for the findings to be significant. With three times the caseload treated in the 1980 s by the Langenbeck technique, a comparable series will be reported in a mere 15 years. A final cohort, which I began to gather in $1989,{ }^{4}$ is being compared with 5 year olds treated by the Langenbeck technique. Treatment in this final cohort embodies Malek's and Delaire's principle of restricting mucoperiosteal undermining to the palatal shelf mucosa. If an overwhelming increase in the ideal relation among the incisor teeth (Angle class I) is found in this group it will encourage surgeons to concentrate on this aspect of planning treatment. But these will be prepubertal results (as were those of Joos) obtained sequentially, not synchronously. In the end only a randomised prospective trial will elucidate this problem.

As is to be expected in papers written by dentists, facial growth is considered to be the preeminent outcome. It is unfortunate that speech, appearance, and social integration, which are the pre-eminent concerns of patients, are more difficult to evaluate, though results with regard to speech that are achieved in Britain compare extremely favourably with any in the English speaking world.

RW PIGOTT

Department of Plastic Surgery Consultant plastic surgeon Frenchay Hospital,

Bristol BS16 1L

1 Markus T, Ward Booth P. Managing cleft lip and palate. $B M$ 1995;311:765-6. (23 September.)

2 Shaw WC, Dahl E. Asher-McDade C, Brattstrom V, McWilliam J, Mars M, et al. Eurocleft. A six centre international study of treatment outcome in patients with cleft lip and palate. Cleft Palate Craniofac $F$ 1992;29:413-8.

3 Ross B. Growth of the facial skeleton following the Malek repair for unilateral cleft lip and palate. Cleft Palate $\mathcal{F} 1$ 995;32:194-8.

4 Murison MSC, Pigott RW. Medial Langenbeck. Experience of a modified von Langenbeck repair of the cleft palate. A preliminary report. Br f Plast Surg 1992;45:454-9.

\section{Specialised multidisciplinary team can solve problems of distance}

EDrroR,-We believe the editorial on managing cleft lip and palate to be misleading. ${ }^{1}$ The Eurocleft study indicated that the outcome of repair of cleft lip and palate was inversely proportional to the number of operators. ${ }^{2}$ To suggest that cleft surgery services should be devolved to local hospitals with multiple operators undertaking few procedures therefore seems illogical and is also at odds with the situation in continental Europe, where cleft surgery is concentrated into a small number of centres.

Anatomical specialisation seems logical, but the suggestion that high volume operators in adult maxillofacial surgery are the best qualified to undertake primary cleft surgery in infants denies the differences in the nature of the tissues (which change appreciably with age), the surgery itself, and the management of children compared with that of adults. In Britain most primary cleft surgery is undertaken by plastic surgeons working 
as part of multidisciplinary teams. Maxillofacial surgeons and ear, nose, and throat surgeons and paediatric surgeons also perform this surgery in other centres. What is important is not the surgical specialty but technical ability and the desire to improve the management of the deformity. Attempts are being made to establish multicentre studies. The need for surgery in patients with cleft lip and palate is rarely disputed, nor is the need to minimise the number of variables to produce meaningful data on the outcome of a specific procedure rather than on whether it has been used appropriately.

Speech therapy for patients is particularly specialised. While at local level there are insufficient patients to justify a specialist, one solution is for a specialist to liaise with local therapists to assess needs and treatment. Providing part of the process at a large sometimes remote, centralised unit does not cause difficulties in other areas: this is exemplified by the work of the Nottingham Paediatric Cochlear Implant Group, which provides a national service with few problems related to distance because of effective communication among all involved.

Excellent results require excellent primary surgery, but, unlike the authors of the editorial, most contemporary British cleft surgeons believe that it is vital that they should attempt to learn from more than one centre of excellence and on a worldwide scale. Functional surgery has theoretical appeal, which has yet to be substantiated in practice. Though it is of potential benefit, it cannot be lauded as the complete solution to the management of cleft lip and palate, as the authors claim..$^{1-3}$ Definitive solutions are elusive, but we believe that the future of cleft surgery lies with specialist multidisciplinary teams providing a complete service to patients and their families with simultaneous participation in multicentre studies. This should be undertaken in an open minded manner without the suggestion that any one surgical specialty has an absolute right to any particular anatomical site or surgical procedure.

AUGUSTIN CABRE Senior house officer in plastic surger KEVIN P GIBBIN

Consultant ear, nose, and throat surgeo MARK HENLEY

Consultant plastic surgeon

ROBERT N NASHED Consultant orthodontist

Subregional Cleft Lip and Palate Service,

City Hospital NHS Trust,

Nottingham NG5 1PB

1 Markus T, Ward Booth P. Managing cleft lip and palate. $B M$ 1995;311:765-6. (23 September.)

2 Shaw WC, Dahl E, Asher-McDade C, Brattstrom V, McWilliam $\mathrm{J}$, Mars $M$, et al. Eurocleft. A six centre international study of J, Mars $\mathrm{M}$, et al. Eurocleft. A six centre international study of treatment outcome in patients
Palate Craniofac $\mathcal{F}$ 1992;29:413-8.

3 Markus AF. Surgery by numbers? Br f Oral Maxillofac Surg 1995;33:205-6.

\section{Language outcomes are important}

EDrroR,-Tony Markus and Peter Ward Booth report that the outcome of cleft lip and palate surgery in Britiain is poor compared with that in other European countries. ${ }^{1}$ It is regrettable that they refer only to the outcome measure of facial growth and make no reference to speech, which is recognised as an equally important indicator of the success of surgery. ${ }^{2}$ Furthermore, when they mention speech and language therapy it is to recommend treatment in local district general hospitals, where, they say, speech and language therapy services are "well placed and funded to provide a comprehensive service." This is a misinformed generalisation. Many district general hospitals do not have clinicians specialising in cleft palate. In advocating the dispersal of speech and language therapy services to generalist clinicians Markus and Ward Booth apparently fail to appreciate the

specialist nature of such therapy for patients with cleft palate. A similar implication is made in their recommendation for surgery to be undertaken by high volume but "non-cleft specialist" operators.

In regional cleft palate centres, specialist speech and language therapists are consultant members of the multidisciplinary team, assessing, diagnosing, and jointly planning management. They are experienced in the use of endoscopy, videofluoroscopy, and other specialised techniques, which are often not available in district general hospitals. They act as advisers to speech and language therapists in the community and are involved in higher education and research.

Continued improvement in the service to patients with cleft palate requires clinical skill and reliable research and audit data. Many surgical and orthodontic colleagues understand that speech problems related to cleft lip and palate are complex and therefore would not advocate the transfer of care exclusively to generalist speech and language therapists. If it is our aim to excel in Britain then it is contradictory to undervalue specialists.

ANNE HARDING Chair, Royal College of Speech and Language Therapists interest group (cleft palate)

Department of Human Communication

De Montfort University,

Scraptoft,
Leicester LE7 9SU

KIM HARL AND Specialist speech and language therapist

St Andrew's Centre for Plastic Surgery,

Billericay,

Essex CM12 OBH

1 Markus T, Ward Booth P. Managing cleft lip and palate. $B M F$ 1995;311:765-6. (23 September.)

2 Dalston RM, Marsh JL, Vig KW, Witzel MA, Bumsted RM. Minimal standards for reporting results of surgery on patients with cleft lip, cleft palate, or both. A proposal. Cleft Palate 1988;25:3-7.

\section{An invitation for Markus to present his results}

EdrToR,-The Craniofacial Society of Great Britain is a multidisciplinary society for the study of cleft lip and palate and other craniofacial anomalies. It exists to promote advances, especially in interdisciplinary research and treatment, and ultimately to enhance the quality of care of affected patients. Central to this research is the objective evaluation of the results of treatment regimens with a view to improving current practices. Such research must be the object of external peer review. Where there are genuine differences of opinion over treatment regimens, care needs to be taken to avoid causing confusion to patients and their relatives.

To this end I was interested to read Tony Markus and Peter Ward Booth's editorial on managing cleft lip and palate, ${ }^{1}$ and an article in a newspaper concerning the work of Markus and his colleagues. ${ }^{2}$ I therefore extend an open invitation to Markus and his colleagues to present their results in a consecutive series of patients, externally verified, to peers at the next annual scientific conference of the Craniofacial Society of Great Britain, to be held at Royal Holloway College, Egham, on 24-26 April next year. This invitation is made in the spirit of promoting constructive dialogue between colleagues and objective evaluation of new treatments and discoveries for the long term benefits of patients.

D A SELL

Craniofacial Society of Great Britain, Speech and Language Therapy Department, Great Ormond Street Hospital,

London WCIN 3JH

1 Markus T, Ward Booth P. Managing cleft lip and palate. $B M \mathcal{F}$

2 Le Fanu J. The anatomy of the face; body and mind. Times 1995 May 4.

\section{Authors' reply}

EDrToR,-While it is encouraging that our editorial generated interest, it is surprising that this response should occur now. The editorial was based on papers published up to four years ago, which when published generated no correspondence. Clearly, a response to the original papers would have allowed the authors to comment and would have encouraged debate in a specialist journal.

It remains worrying that $\mathbf{M} J$ Timmons, $R$ W Pigott, and Augustin Cabre and colleagues fail wholeheartedly to accept the accumulating evidence which suggests that we must try harder to improve the outcome of cleft surgery in Britain. There also seems to be a continued reluctance (though not on the part of Cabre and colleagues) to acknowledge the importance of anatomical specialisation despite this being the norm in other surgical disciplines and a prerequisite to the establishment of cancer centres. Timmons, Pigott, and Anne Harding and Kim Harland criticise the study as not evaluating every aspect of outcomes of cleft surgery. While in principle we support their view, it is important to recall studies, which showed that in the past most cleft surgeons kept no records at all. ${ }^{1}$

We are encouraged that Pigott has radically altered his technique at least three times to seek improvements; the last technique used is not dissimilar to ours. ${ }^{2}$ We share his view that dental training is a valuable part of the training of a cleft surgeon. Pigott will no doubt be pleased to note the good results of evaluation of nasal form with the Delaire technique reported by maxillofacial surgeons with a dental and medical training. ${ }^{3}$ There are, of course, other papers by maxillofacial surgeons that look at other aspects besides facial growth.4

Timmons's letter is confusing since none of the papers quoted audited primary cleft surgery.

We agree with Harding and Harland, who emphasise the need for specialist speech and language therapists. Such therapists are available in increasing numbers in larger district hospitals, where they can study outcomes and carry out research-features not obviously forthcoming from some of the large regional centres.

Finally, we wish to comment on the letter from the Craniofacial Society, which shares our enthusiasm for publishing our views and results in peer reviewed journals. We are sure, however, that the society will not be surprised that we wish to present and publish our findings at our own meetings and in our journal. The meetings and journal of the British Association of Oral and Maxillofacial Surgeons are always well supported by all specialties from Britain and abroad, including many members of the Craniofacial Society. It is undesirable to present the same material at different meetings and certainly wrong to publish in two journals. Naturally, as new data become available we would consider reporting them to the society, but it is just one of many such groups.

There is no doubt that cleft surgery is undergoing a most rigorous appraisal, which is as overdue as it is desirable. If our editorial, or the involvement of British oral and maxillofacial surgeons in primary cleft surgery, in some way helps this process we will be delighted. Accepting the status quo is, however, not good enough for our patients.

TONY MARKUS Consultant oral and maxillofacial surgeon

Oral and Maxillofacial Surgery,

Poole Hospital, Poole BH15 2JB

PETER WARD BOOTH

Oral and Maxillofacial Surgery,

Queen Victoria Hospital,

East Grinstead RH19 3DZ

1 Williams A, Shaw WC, Devlin HB. Provision of services for cleft lip and palate in England and Wales. BMF 1994;309:1552-3. 